\title{
The effectiveness of ibuprofen and lorazepam combination therapy in treating the symptoms of acute Migraine: A randomized clinical trial
}

\author{
Reza Ebrahimi Rad ${ }^{1}$, Fatemeh Ghaffari ${ }^{2}$, Zahra Fotokian $^{2}$, Azadeh Ramezani ${ }^{3}$
}

${ }^{1}$ M.D., Neurologist, Assistant Professor, Department of Medicine, Islamic Azad University, Tonekabon Branch, Tonekabon, Mazandaran, Iran

${ }^{2}$ Ph.D. of Nursing, Assistant Professor, Ramsar Nursing Care Research Center, School of Nursing and Midwifery, Babol University of Medical Sciences, Babol, Mazandaran, Iran

${ }^{3}$ Medical Student, Department of Medicine, Islamic Azad University, Tonekabon Branch, Tonekabon, Mazandaran, Iran

\section{Type of article: Original}

\begin{abstract}
Background: Migraine is a common, episodic and debilitating disease. The migraineur not only suffers from pain, but also lives with a diminished to poor quality of life. Several medicinal therapies are used to abate the debilitating symptoms of this disease.

Objective: The present study was conducted to determine the effectiveness of Ibuprofen and Lorazepam combination therapy in treating the symptoms of acute migraine.

Methods: The present randomized clinical trial study used the pretest-posttest design with three comparison treatments, to examine 90 patients with an average of two to six attacks per month and an initial diagnosis of migraine based on the International Headache Society (HIS) criteria. The study was conducted on patients during the first half of 2014 with a diagnosis of acute migraine attack who were referred to Babol Ayatollah Rouhani Hospital in Iran. The patients were randomly divided into three groups of 30 . The first group was administered $200 \mathrm{mg}$ Ibuprofen capsules, the second group $400 \mathrm{mg}$ Ibuprofen capsules and the third group a combination of $200 \mathrm{mg}$ Ibuprofen capsules and $1 \mathrm{mg}$ Lorazepam tablets. The medications were taken in the presence of the researcher. A checklist was used to assess the severity of headache and other migraine symptoms such as nausea, vomiting, photophobia and phonophobia in the patients, before and two hours after the intervention. Data were analyzed in SPSS-18 using the Mann-Whitney test, the McNemar test, Wilcoxon's test, the NOVA and the Chisquared test at the significance level of $\mathrm{p}<0.05$, and power analysis with 30 patients in each group to perform this study was $0.8(1-\beta)$.

Results: The mean age of participants was reported as $52 \pm 8$ years and the condition was more frequent in women $(56 \%)$. All three treatment regimens reduced the severity of headache significantly in the patients $(\mathrm{p}<0.001)$; nevertheless, the combination therapy used, produced the lowest mean severity of headache $(\mathrm{p}<0.001)$. The highest reduction in nausea and vomiting was (3.3\%). None of the patients in either of the three groups reported phonophobia after the intervention, but only the patients in the combination therapy group reported no instance of photophobia.

Conclusions: Given the greater effectiveness of combination therapy with Ibuprofen and Lorazepam in alleviating the symptoms of acute migraine compared to single-drug treatments with Ibuprofen, Lorazepam is recommended to be used as a first line treatment for acute migraine.

Clinical trial registration: The trial was registered at the Thai Clinical Trials Registry (TCTR) (http://www.clinicaltrials.in.th/) with the ID: TCTR20160927003.

Funding: The authors received no financial support for the research, authorship, and/or publication of this article. Keywords: Migraine, Acute, Treatment, Ibuprofen, Lorazepam
\end{abstract}

\section{Corresponding author:}

Assistant Professor Dr. Zahra Fotokian, Ramsar Nursing Care Research Center, School of Nursing and Midwifery, Babol University of Medical Sciences, Babol, Mazandaran, Iran.

Tel: +98.9127177552, Fax: +98.55226413, Email: zfotoukian@yahoo.com

Received: May 18, 2016, Accepted: December 16, 2016, Published: March 2017

iThenticate screening: November 11, 2016, English editing: February 02, 2017, Quality control: March 04, 2017

(C) 2017 The Authors. This is an open access article under the terms of the Creative Commons Attribution-NonCommercialNoDerivs License, which permits use and distribution in any medium, provided the original work is properly cited, the use is non-commercial and no modifications or adaptations are made. 


\section{Introduction}

The chief reason for $4.4 \%$ of all consultations in general practice is headache (1), it accounts for almost $5 \%$ of admissions to hospital (2), and around $20 \%$ of neurology outpatient consultations (3). Migraine is a chronic neurological disorder and its characteristics are paroxysmal bouts of headache and associated symptoms which often last between 4-72 hours (4). Occasionally, migraine starts with signs such as the appearance of zigzag lines or stars in the field of vision (indicative of classic migraine) and is accompanied by symptoms such as nausea, vomiting, photophobia and phonophobia during attacks. According to a World Health Organization report, migraine headache is ranked as the 19th most debilitating disorder across the world (5). More than $20 \%$ of people worldwide will be affected by migraine at some point in their lives. According to epidemiological studies, approximately $4.5 \%$ of the population of Western Europe has suffered from headache on at least 15 days per month. Around $1 \%$ of the world's population may have suffered from chronic migraine (7) according to global studies. Chronic migraine is accountable for substantial economic loss on societies (8). According to the WHO Global Burden of Disease figures in 2012, migraine is so common that, even considering the large number of people who simply regard it as an inconvenience, the increasing problem of the disorder has been the reason it is ranked in the top 40 conditions that cause worldwide disability, ranking only behind stroke, meningitis and epilepsy. In the UK, it ranks third behind stroke and dementia, accounting for the annual loss of 230,000 DALYs (Disability-Adjusted Life Years) (9). Its frequency, severity, and impact on quality of life vary widely (10). Earlier studies revealed that given the large amount of associated disability and financial costs to society, headache disorders are considered a public-health concern. Due to the impact that headache disorders have on productive years (late teens to 50s), it is suggested there are enormous financial damages to society - primarily from lost working hours and reduced productivity. For example, every year in the UK, up to 25 million working- or school-days are lost because of migraine alone. In a previous survey, headache ranked high among reasons for consulting medical practitioners as one-third of total neurological consultations were for headache (11). Specialized training of health professionals is necessary in order to give the appropriate treatment for headache disorders, which requires, accurate diagnosis and recognition of the disorder, suitable treatment process with cost-effective medication, basic lifestyle changes, and patient instruction. Analgesics, anti-emetics, anti-migraine medications, and prophylactic medications are the main classes of medications used for headache disorders (11). A recognized group of drugs which can be used for reducing headache are Non-Steroidal Anti Inflammatory Drugs (NSAIDs) (5). Ibuprofen is one of the widely used NSAIDs $(3,7)$, and is an effective inhibitor of cyclooxygenase, resulting in the inhibition of prostaglandin synthesis. According to clinical studies, in the treatment of migraine headache, Ibuprofen provides a more effective headache relief than placebo (7). Ibuprofen 200 and $400 \mathrm{mg}$ are effective in alleviating headache intensity and rendering patients pain-free within 2 hours, the available evidence suggests. With $400 \mathrm{mg}$ dosing, photophobia and phonophobia improved, however, due to the limited data available and the insufficient evidence, more studies are required for the future (3). No studies have yet investigated the effectiveness of Ibuprofen and Lorazepam combination therapy in treating the symptoms of acute migraine attacks. The high prevalence of migraine headaches urges patients and medical professionals to choose the best possible treatment for treating their symptoms. The present study was thus conducted to determine the effectiveness of Ibuprofen and Lorazepam combination therapy in treating the symptoms of acute migraine.

\section{Material and Methods}

\subsection{Research design and setting}

The present randomized clinical trials study used the pretest-posttest design with three comparison treatments to examine patients presenting to Ayatollah Rouhani Hospital in Babol from March to September 2014 with a diagnosis of acute migraine attacks. The study was conducted on patients with a diagnosis of acute migraine attack who were referred to Ayatollah Rouhani Hospital in Babol, Iran.

\subsection{Outcome}

The severity of headache was assessed verbally in all three groups before and two hours after the administration of the medications, and a score of zero was given to patients who said they experienced no headaches, 1 to those who experienced a mild headache, 2 to those who experienced a moderate headache and 3 to those who experienced a severe headache (2). A checklist was then used to collect data on other symptoms such as nausea, vomiting, photophobia and phonophobia in all three groups before and two hours after the administration of the medications and in the presence of the researcher. 


\subsection{Procedures}

After obtaining permission from Babol University of Medical Sciences, 90 patients with an average of two to six attacks per month and an initial diagnosis of migraine based on the International Headache Society (HIS) criteria, were selected through convenience sampling. The study exclusion criteria consisted of being allergic to medications treating the symptoms of acute migraine, having taken Ibuprofen 6 hours prior to the study, having taken Benzodiazepine in the past 24 hours, suffering from secondary headaches and having physical diseases and neurological or psychiatric disorders and also pregnancy and the use of hormonal contraceptives (in women). To eliminate the confounding factors, the groups were matched in terms of age and gender.

\subsection{Intervention}

After briefing participants about the type of intervention employed in the study, written consent was obtained from them and they were then randomly divided into three groups of 30. The first group was administered $200 \mathrm{mg}$ Ibuprofen capsules, the second group $400 \mathrm{mg}$ Ibuprofen capsules and the third group a combination of $200 \mathrm{mg}$ Ibuprofen capsules and $1 \mathrm{mg}$ Lorazepam tablets. The Ibuprofen capsules used in this study were made by Aria Co Pharmaceuticals (Iran) and the Lorazepam tablets by Dr. Obeidi Co Pharmaceuticals (Iran).

\subsection{Statistical analysis}

Data were analyzed in SPSS-18 (SPSS, Inc., Chicago, IL, USA) using the Mann-Whitney test, the McNemar test, Wilcoxon's test, the NOVA and the Chi-squared test at the significance level of $\mathrm{P}<0.05$ and power analysis with 30 patients in each group to perform this study was $0.8(1-\beta)$.

\subsection{Ethics of research}

The Ethics Committee Branch of Tonekabon Islamic Azad University has approved the study design. Participation in the study is voluntary. Each of the study participants were able to recognize and feel themselves and leave without any response. They were required to read the informed consent form and sign if they wished to participate in the study. The patients were advised to report any side effect up to $24 \mathrm{~h}$ after medications. To prevent physical and moral losses, the patients were advised to report any side effect up to 24 hours after medications.

\section{Results}

The mean age of participants was $52 \pm 8$ years and the condition was more frequent in women (56\%). There were no significant differences between the three groups in terms of gender distribution $(\mathrm{p}=0.38)$ or mean age $(\mathrm{p}=0.327)$. The results obtained, showed that all three treatment regimens reduced the severity of headaches significantly, but that the Ibuprofen and Lorazepam combination therapy led to the lowest mean severity of headache (Table 1). The pairwise comparison of the groups showed no significant differences between the $200 \mathrm{mg}$ and the $400 \mathrm{mg}$ Ibuprofen groups in their post-intervention severity of headache $(\mathrm{p}=0.219)$; however, the combination therapy group had a significantly different post-intervention severity of headache compared to the $200 \mathrm{mg}(\mathrm{p}=0.001)$ and the $400 \mathrm{mg}$ Ibuprofen $(\mathrm{p}=0.001)$ groups. All three treatment regimens managed to significantly abate nausea and vomiting two hours after administration, but the McNemar test showed a significant difference between the groups. The results showed no significant differences between the $200 \mathrm{mg}$ and the $400 \mathrm{mg}$ Ibuprofen groups in their reduction of nausea and vomiting, while the highest reduction in these symptoms $(3.3 \%)$ was observed in the combination therapy group. The results of the present study showed that all three treatment regimens reduced photophobia significantly two hours after administration. Also, the results obtained showed no significant differences between the $200 \mathrm{mg}$ and the $400 \mathrm{mg}$ Ibuprofen groups in their reduction of photophobia. However, none of the patients in the combination therapy group reported photophobia any longer. The results of the present study showed that none of the patients in either of the three groups reported phonophobia after the intervention (Table 2).

Table 1. The severity of headache in the three groups before and after the intervention

\begin{tabular}{|l|l|l|l|l|l|l|}
\hline Group & Occasion & Min & Max & Mean & Median & p-value \\
\hline \multirow{2}{*}{$200 \mathrm{mg}$ Ibuprofen } & Before & 2 & 3 & 2.5 & 3 & 0.001 \\
\cline { 2 - 9 } & After & 0 & 3 & 1.6 & 2 & \\
\hline \multirow{2}{*}{$400 \mathrm{mg}$ Ibuprofen } & Before & 1 & 3 & 2.4 & 2.5 & \multirow{2}{*}{0.001} \\
\cline { 2 - 8 } & After & 0 & 2 & 1.3 & 2 & \\
\hline \multirow{2}{*}{$200 \mathrm{mg}$ Ibuprofen + 1 mg Lorazepam } & Before & 2 & 3 & 2.7 & 3 & \multirow{2}{*}{0.001} \\
\cline { 2 - 7 } & After & 0 & 3 & 0.7 & 1 & \\
\hline
\end{tabular}


Table 2. The frequency distribution and percentage of nausea and vomiting, photophobia and phonophobia in the three groups

\begin{tabular}{|c|c|c|c|c|c|c|c|c|}
\hline \multirow{3}{*}{\multicolumn{2}{|c|}{ Symptoms of headache }} & \multicolumn{6}{|c|}{ Groups; n (\%) } & \multirow{3}{*}{$\begin{array}{l}\mathrm{p}- \\
\text { value }\end{array}$} \\
\hline & & \multicolumn{2}{|c|}{$200 \mathrm{mg}$ Ibuprofen } & \multicolumn{2}{|c|}{400 mg Ibuprofen } & \multicolumn{2}{|c|}{$\begin{array}{l}200 \text { mg Ibuprofen+1 } \\
\text { mg Lorazepam }\end{array}$} & \\
\hline & & With & Without & With & Without & With & Without & \\
\hline \multirow{2}{*}{$\begin{array}{l}\text { Nausea and } \\
\text { Vomiting }\end{array}$} & Before & 28 (93.3) & $2(6.7)$ & 29 (96.7) & $1(3.3)$ & $30(100)$ & $0(0)$ & \multirow[t]{2}{*}{0.001} \\
\hline & After & $7(23.3)$ & $23(76.7)$ & $4(13.3)$ & $26(86.7)$ & $1(3.3)$ & 29 (96.7) & \\
\hline \multirow[t]{2}{*}{ Photophobia } & Before & $20(66.7)$ & $10(33.3)$ & $19(63.3)$ & $11(36.7)$ & $21(70)$ & $9(30)$ & \multirow[t]{2}{*}{0.001} \\
\hline & After & $3(10)$ & $27(90)$ & $2(6.7)$ & 28 (93.3) & $0(0)$ & $30(100)$ & \\
\hline \multirow[t]{2}{*}{ Phonophobia } & Before & $16(53.3)$ & $14(46.7)$ & $8(26.7)$ & $22(73.3)$ & $10(33.3)$ & $20(66.7)$ & \multirow[t]{2}{*}{0.001} \\
\hline & After & $0(0)$ & $30(100)$ & $0(0)$ & $30(100)$ & $0(0)$ & $30(100)$ & \\
\hline
\end{tabular}

\section{Discussion}

The results of the present study suggest that Ibuprofen can effectively alleviate headache in patients with acute migraine and also that there are no significant differences between $200 \mathrm{mg}$ and $400 \mathrm{mg}$ doses of Ibuprofen in controlling the severity of headache. Codispoti et al. (1) also found no significant differences between $200 \mathrm{mg}$ and $400 \mathrm{mg}$ doses of Ibuprofen in controlling the severity of headache in their study; however, they found that the 400 $\mathrm{mg}$ dose of Ibuprofen was more effective in patients with more severe headaches $(\mathrm{P}<0.04)$, which is consistent with the results of other studies. Misra et al. (12) also compared the effectiveness of Rofecoxib and Ibuprofen in the treatment of acute migraine and showed that both were significantly effective in alleviating headache two hours after administration. Diener et al. (7) compared the effectiveness of effervescent Acetylsalicylic Acid (ASA), Sumatriptan, and Ibuprofen in the treatment of acute migraine attacks and showed that the percentage of patients with a headache severity reduced from severe or moderate to mild or non-existent was $52.5 \%$ in the case of ASA administration, $60.2 \%$ in the case of Ibuprofen administration, $55 \%$ in the case of Sumatriptan administration and $3.6 \%$ in the case of placebo administration. All treatments were significantly more effective than the administration of placebos $(\mathrm{p}<0.001)$ and no significant differences were observed between the effects produced by effervescent ASA, Ibuprofen and Sumatriptan, which is inconsistent with the results of other studies. For instance, in a study conducted by Goldstein et al. (2006), the rate of recovery from symptoms of acute migraine was significantly higher in the AAC group than in the Ibuprofen group $(\mathrm{p}<0.03)$ (9). In another study, Misra et al. (12) found that treatment with Rizatriptan produced a significantly higher 20-hour recovery from headache compared to treatment with Ibuprofen or placebos. The results of the present study confirmed the higher effectiveness of combination therapy with $200 \mathrm{mg}$ Ibuprofen and $1 \mathrm{mg}$ Lorazepam compared to single-drug treatments with $200 \mathrm{mg}$ or $400 \mathrm{mg}$ Ibuprofen in reducing the severity of headache and other symptoms of acute migraine. Ibuprofen is a non-steroidal antiinflammatory drug with a mechanism of action that inhibits prostaglandin synthesis through cyclooxygenases (13). Benzodiazepines may have an improved analgesic effect caused by the increased gamma-aminobutyric acid (GABA) activity on the GABA receptors in the dorsal horn of the spinal cord (14). Some researchers believe that benzodiazepines are able to increase the threshold of pain (15), and some others believe that these drugs have analgesic effects, while others believe that they have no effects whatsoever on the pain threshold (16). Doležal and Kršiak (17) investigated the analgesic effects of Ibuprofen and Alprazolam in their experiments on rats and showed that the analgesic effects of Ibuprofen are only slightly enhanced by the simultaneous administration of Alprazolam. In one study, Dionne and Singer investigated the effectiveness of Ibuprofen and Diazepam in the treatment of chronic orofacial muscle pain and showed a significant reduction in the severity of pain with a Diazepam and Ibuprofen combination therapy and also with a single-drug treatment with Diazepam, but no significant reduction with the administration of placebos or with single-drug treatments with Ibuprofen. The analysis of variance attributed the effectiveness of the combination therapy to Diazepam and not to Ibuprofen and these drugs did not reinforce each other's effects (6). Russell et al. (10) studied the effectiveness of treatment with Ibuprofen and Alprazolam in patients with fibrosis and observed a good clinical recovery and pain relief in patients who had been administered both medications. In the present study, Ibuprofen and Lorazepam managed to alleviate pain when administered together. Lorazepam thus appears to enhance the analgesic effects of Ibuprofen. According to the results obtained, all three medications can improve nausea, vomiting, photophobia and phonophobia significantly. However, a combination therapy with Ibuprofen and Lorazepam is much more effective in abating these symptoms. No studies have yet investigated the effectiveness of the concurrent administration of Ibuprofen and Lorazepam in controlling these symptoms; however, combination therapies have been found to be more effective in controlling these symptoms. In one study, Suthisisang et al. (3) showed that the administration of $400 \mathrm{mg}$ doses of Ibuprofen 
improved photophobia by $30 \%$ and phonophobia by $49 \%(\mathrm{p}<0.001)$, suggesting significantly better results compared to the results produced with the administration of $200 \mathrm{mg}$ Ibuprofen. In a study conducted by Misra et al., $50 \%$ of the patients showed improvements in nausea, vomiting, photophobia and phonophobia with the administration of a $400 \mathrm{mg}$ dose of Ibuprofen (12).

\section{Study limitations}

The drugs consumed in 3 groups should have been identified by researchers to analyze data and conduct the research. Then blinding would have been possible. Since BZD class drugs like Lorazepam are not efficient enough during the curing process of acute migraine, prescribing Lorazepam exclusively does not seem to fit with the ethics or scientific limitations. For this reason we didn't apply such a group of 30 patients to our study, which can be considered as a limitation.

\section{Conclusions}

Given the greater effectiveness of combination therapy with Ibuprofen and Lorazepam in alleviating the symptoms of acute migraine compared to single-drug treatments with Ibuprofen, Lorazepam is recommended to be used as a first line treatment for acute migraine. This study is recommended to be repeated with larger sample sizes. A person who uses lorazepam or another benzodiazepine to treat chronic headaches, is in danger of experiencing serious side effects. Drugs such as lorazepam can even cause headaches when taken for long periods. Mixing benzodiazepines with other medications can be dangerous. It is especially dangerous to mix benzodiazepines with opioid pain relievers. When the two drugs are mixed, the effects of both drugs are increased and the chance of overdose is much higher.

\section{Acknowledgments:}

The researchers would like to express their gratitude to all the participating patients. This research is part of a thesis for the reception of (MD) degree. The authors wish to express their gratitude to all participants and the Research Deputy of Azad Islamic University (Tonekabon branch).

\section{Trial Registration:}

The trial was registered at the Thai Clinical Trials Registry (TCTR) (http://www.clinicaltrials.in.th) with the ID: TCTR20160927003

\section{Funding:}

The authors received no financial support for the research, authorship, and/or publication of this article.

\section{Conflict of Interest:}

There is no conflict of interest to be declared.

\section{Authors' contributions:}

All authors contributed to this project and article equally. All authors read and approved the final manuscript.

\section{References:}

1) Codispoti JR, Prior MJ, Fu M, Harte CM, Nelson EB. Efficacy of nonprescription doses of ibuprofen for treating migraine headache. A randomized controlled trial. Headache. 2001; 41(7): 665-79. doi: 10.1046/j.1526-4610.2001.041007665.x. PMID: 11554954.

2) Tfelt - Hansen P, Block G, Dahlöf C, Diener HC, Ferrari M, Goadsby P, et al. Guidelines for controlled trials of drugs in migraine. Cephalalgia. 2000; 20(9): 765-86. doi: 10.1046/j.1468-2982.2000.00117.x. PMID: 11167908 .

3) Suthisisang C, Poolsup N, Kittikulsuth W, Pudchakan P, Wiwatpanich P. Pain Management: Efficacy of low-dose ibuprofen in acute migraine treatment: systematic review and meta-analysis. Annals of Pharmacotherapy. 2007; 41(11): 1782-91. doi: 10.1345/aph.1K121.

4) Kalra AA, Elliott D. Acute migraine: Current treatment and emerging therapies. Ther Clin Risk Manag. 2007; 3(3): 449-59. PMID: 18488069, PMCID: PMC2386351.

5) Gholamreza MM, Kheiri S, Khosravi S, Koshdel A, Keyvani Z, Amini Z. Iron therapy and migraine headache. J Shahrekord Univ Med Sci. 2012; 13(6): 56-62.

6) Singer E, Dionne R. A controlled evaluation of ibuprofen and diazepam for chronic orofacial muscle pain. J Orofac Pain. 1996; 11(2): 139-46. PMID: 10332320. 
7) Diener H, Bussone G, De Liano H, Eikermann A, Englert R, Floeter T, et al. Placebo - controlled comparison of effervescent acetylsalicylic acid, sumatriptan and ibuprofen in the treatment of migraine attacks. Cephalalgia. 2004; 24(11): 947-54. doi: 10.1111/j.1468-2982.2004.00783.x.

8) Silberstein SD, Marmura MJ. Acute Migraine Treatment. Headache. 2015; 55(1): 1-2. doi: 10.1111/head.12504.

9) Goldstein J, Silberstein SD, Saper JR, Ryan RE, Lipton RB. Acetaminophen, Aspirin, and Caffeine in Combination Versus Ibuprofen for Acute Migraine: Results From a Multicenter, Double - Blind, Randomized, Parallel - Group, Single - Dose, Placebo - Controlled Study. Headache. 2006; 46(3): 444-53. doi: 10.1111/j.1526-4610.2006.00376.x.

10) Russell IJ, Fletcher EM, Michalek JE, McBroom PC, Hester G. Treatment of primary fibrositis/fibromyalgia syndrome with ibuprofen and alprazolam. A double-blind, placebo-controlled study. Arthritis Rheum. 1991; 34(5): 552-60. doi: 10.1002/art.1780340507. PMID: 2025309.

11) Headache Classification Committee of the International Headache Society (IHS). The international classification of headache disorders, (beta version). Cephalalgia. 2013; 33(9): 629-808. doi: 10.1177/0333102413485658. PMID: 23771276.

12) Misra UK, Kalita J, Yadav RK. Rizatriptan vs. ibuprofen in migraine: a randomised placebo-controlled trial. The journal of headache and pain. 2007; 8(3): 175-9. doi: 10.1007/s10194-007-0386-7.

13) Björkman R. Central antinociceptive effects of non - steroidal anti - inflammatory drugs and paracetarmol. Experimental studies in the rat. Acta Anaesthesiol Scand Suppl. 1995; 103: 1-44. PMID: 7725891.

14) Luger TJ, Hayashi T, Lorenz IH, Hill HF. Mechanisms of the influence of midazolam on morphine antinociception at spinal and supraspinal levels in rats. Eur J Pharmacol. 1994; 271(2): 421-31. doi: 10.1016/0014-2999(94)90802-8. PMID: 7705442.

15) Tatsuo M, Yokoro C, Salgado J, Pesquero S, Santana M, Francischi J. Hyperalgesic effect induced by barbiturates, midazolam and ethanol: pharmacological evidence for GABA-A receptor involvement. Braz J Med Biol Res. 1997; 30: 251-6. doi: 10.1590/S0100-879X1997000200015.

16) Tejwani GA, Rattan AK, Sribanditmongkol P, Sheu MJ, Zuniga J, McDonald JS. Inhibition of morphineinduced tolerance and dependence by a benzodiazepine receptor agonist midazolam in the rat. Anesth Analg. 1993; 76(5): 1052-60. PMID: 8484507.

17) Doležal T, Kršiak M. Augmentation of analgesic effect of ibuprofen by alprazolam in experimental model of pain. Physiol Res. 2002; 51(2): 179-84. PMID: 12108928. 